\title{
Zinc at Sub-Cytotoxic Concentrations Induces Heme Oxygenase-1 Expression in Human Cancer Cells
}

\author{
Jing Xue $e^{a, b, c}$ Shuai Wang ${ }^{c}$ Jinchang Wu ${ }^{a, b}$ Bethany N. Hannafon ${ }^{c}$ Wei-Qun Ding \\ aSchool of Radiation Medicine and Protection, Soochow University, Suzhou; ${ }^{b}$ Department of Radio- \\ Oncology, Nanjing Medical University Affiliated Suzhou Hospital, Suzhou, P. R. China; 'Department of \\ Pathology, University of Oklahoma Health Sciences Center, Oklahoma City, OK, USA
}

\section{Key Words}

Heme oxygenase $1 \cdot$ Zinc • Cancer • Nrf2 • A2780 • MDA-MB-231

\begin{abstract}
Background/Aims: This study investigated the effects of zinc on heme oxygenase-1 (HO1) expression in human cancer cells. Methods/Results: Zinc at sub-cytotoxic concentrations $(50-100 \mu \mathrm{M})$ induces HO-1 expression in the MDA-MB-231 (human breast cancer) and A2780 (human ovarian cancer) cell lines in a concentration- and time-dependent manner. The induction of HO-1 by zinc was detected after 4-6 hours of treatment, reached maximal level at 8 hours, and declined thereafter. Using a human HO-1 gene promoter reporter construct, we identified two antioxidant response elements (AREs) that mediated the zinc-induced increase in $\mathrm{HO}-1$ gene transcription, indicating that the nuclear factor (erythroid-derived 2)like 2 (Nrf2) signaling pathway is involved in this event. This assumption was supported by the observations that knockdown of Nrf2 expression compromised the zinc-induced increase in HO-1 gene transcription, and that zinc increased Nrf2 protein expression and the Nrf2 binding to the AREs. Additionally, we found that the zinc-induced HO-1 gene transcription can be enhanced by clioquinol, a zinc ionophore, and reversed by pretreatment with TPEN, a known zinc chelator, indicating that an increase in intracellular zinc levels is responsible for this induction. Conclusion: These findings demonstrate that zinc at sub-cytotoxic concentrations induces HO-1 expression in human cancer cells. The biological significance of this induction merits further investigation.
\end{abstract}




\section{Introduction}

Heme oxygenase-1 (HO-1) is a microsomal enzyme that catalyzes the rate-limiting step in the degradation of heme resulting in equal-molar quantities of carbon monoxide (CO), iron ions and biliverdin. Biliverdin can be further converted by biliverdin reductase to bilirubin, which possesses antioxidant activity. It is well-accepted that HO-1 is a cytoprotective enzyme and the enzymatic activity of HO-1 results in decreased oxidative stress, attenuated inflammatory response, and a lower rate of apoptosis [1]. However, in cancer cells, HO-1 expression is generally higher than that in normal cells which often leads to resistance to chemotherapy [2]. For this reason, HO-1 is currently considered a cancer therapeutic target $[3,4]$.

Zinc is an essential trace element in plants and animals functioning in structural, enzymatic catalyst, and regulatory activities in these cells [5]. Zinc deficiency has been identified in several forms of malignancy including breast cancer, and is believed to be an etiological factor in carcinogenesis [6-8]. We, and others, have recently reported that zinc ionophores, such as clioquinol, are likely a new group of anticancer agents targeting both breast and ovarian cancer cells [9-11]. Zinc at cytotoxic concentrations is targeted to lysosomes whereby it may induce apoptosis in breast cancer cells [12]. Furthermore, at cytotoxic concentrations, zinc also modulates post-transcriptional regulation of gene expression involving the microRNA processing machinery [13]. However, the effect of zinc at sub-cytotoxic concentrations on HO-1 expression in breast and ovarian cancer cells has not been investigated.

The present study has examined the effects of zinc on HO-1 expression in human breast and ovarian cancer cell model systems. We found that zinc induces HO-1 expression and that this induction is mediated through the Nrf2 signaling pathway.

\section{Materials and Methods}

\section{Materials}

The pGL3/4.5-HO-1 luciferase reporter construct containing the 4.5 kilobase fragment of the human HO-1 gene promoter was kindly provided by Dr. Anupam Agarwal (University of Alabama at Birmingham, Birmingham, AL). The HO-1 3'-UTR and the glyceraldehyde-3-phosphate-dehydrogenase (GAPDH) 3'-UTR reporter constructs were purchased from SwitchGear Genomics (Menlo Park, CA). The Dual-Luciferase Reporter kit was from Promega (Madison, WI). The QuikChange Site-Directed Mutagenesis Kit was from Stratagene (La Jolla, CA). The Chromatin Immunoprecipitation (ChIP) Assay Kit was from Millipore (Temecula, CA). $\mathrm{ZnCl}_{2}$, N-Acetyl-L-cycteine (NAC), N,N,N',N'-Tetrakis (2-pyridylmethyl) ethylenediamine(TPEN), ammonium tetrathiomolybdate (TM), clioquinol, and other chemical reagents were purchased from Sigma-Aldrich (St. Louis, MO).

\section{Cell culture}

The human ovarian cancer cell line (A2780) was generously provided by Dr. Stephen Howell (University of California, San Diego), and maintained in RPMI 1640 medium supplemented with 10\% fetal bovine serum and antibiotics. The human metastatic breast adenocarcinoma cell line (MDA-MB-231) was obtained from the American Type Culture Collection. The human umbilical vein cell line (EA.hy926) was a kind gift from Dr. Doris M. Benbrook (University of Oklahoma Health Sciences Center, Oklahoma City). Both MDAMB-231 and EA.hy926 cells were grown in DMEM with supplements same as that in RPMI 1640 medium. Cells were cultured in a humidified environment containing $5 \% \mathrm{CO}_{2}$ at $37^{\circ} \mathrm{C}$, and passaged twice a week.

\section{Western blot analysis}

Western blot was performed as we previously described $[9,14]$. Briefly, for cellular protein isolation, cells were lysed with lysis buffer containing $50 \mathrm{mM}$ Tris, pH 7.4, $50 \mathrm{mM} \mathrm{NaCl}, 0.5 \%$ NP-40, $50 \mathrm{mM} \mathrm{NaF}, 1 \mathrm{mM}$ $\mathrm{Na}_{3} \mathrm{VO}_{4}, 1 \mathrm{mM}$ phenylmethylsulfonyl fluoride (PMSF), $25 \mu \mathrm{g} / \mathrm{ml}$ leupeptin, and $25 \mu \mathrm{g} / \mathrm{ml}$ aprotinin, sonicated on ice for 6 strokes of 10 seconds each, and centrifuged at $15,000 \times \mathrm{g}$ for 15 minutes to remove insoluble material. For nuclear protein extraction, cells were detached by adding $2.5 \mathrm{ml}$ wash buffer (for a 100-mm 
dish) containing 1 mM HEPES, pH 7.9, $150 \mu \mathrm{M} \mathrm{MgCl}_{2}, 1 \mathrm{mM} \mathrm{KCl}, 50 \mu \mathrm{M}$ dithiothreitol (DTT), $100 \mu \mathrm{M}$ PMSF, $200 \mathrm{ng} / \mathrm{ml}$ aprotinin, $1 \mu \mathrm{g} / \mathrm{ml}$ leupeptin, $200 \mathrm{ng} / \mathrm{ml}$ pepstatin A, and $0.01 \% \mathrm{NP}-40$. The lysate was centrifuged at 4,550×g for $2 \mathrm{~min}$ to collect nuclei. Pellets were re-suspended in $50 \mu \mathrm{l}$ suspension buffer containing 25\% glycerol, $420 \mathrm{mM} \mathrm{NaCl}, 1.5 \mathrm{mM} \mathrm{MgCl} 2,0.2 \mathrm{mM}$ EDTA, $0.5 \mathrm{mM}$ DTT, $1 \mathrm{mM}$ PMSF, $2 \mu \mathrm{g} / \mathrm{ml}$ aprotinin, 10 $\mu \mathrm{g} / \mathrm{ml}$ leupeptin, $2 \mu \mathrm{g} / \mathrm{ml}$ pepstatin A. The suspension was incubated on ice for 30 minutes and centrifuged for 20 minutes at 15,000×g to remove insoluble material. About 30-40 $\mu \mathrm{g}$ of protein from each sample was separated on a 10\% SDS-PAGE gel, transferred to a PVDF membrane, and blotted with antibodies against HO-1 (Stressgen, Ann Arbor, MI), Nrf2 (Santa Cruz, CA), PPAR $\alpha$ (Abcam, MA), GAPDH (ProMab Biotechnologies, $\mathrm{CA}$ ), or $\beta$-actin (Sigma-Aldrich, MO).

\section{Luciferase reporter activity assay}

Approximately $3 \times 10^{6}$ A2780 cells were seeded in 100 -mm cell culture dishes. After 24 hours of plating, cells were transfected with the pGL3/4.5-HO-1, the HO-1 3'-UTR, or the GAPDH 3'-UTR reporter constructs using the Fugene HD transfection reagent (Promega, Madison, WI) as previously described [14, 15]. The next day, cells were lifted and seeded into a 24 -well plate at $2 \times 10^{5}$ per well. 48 hours after transfection, cells were treated with various reagents for indicated durations and concentrations. Cell lysates were prepared and luciferase activity was assayed using the Dual-Luciferase Reporter kit (Promega, Madison, WI) as described $[14,15]$. The firefly luciferase activity was normalized to the amount of protein used for luciferase activity assay for each sample. The data are expressed as percentages of luciferase activity detected in untreated control cells.

SiRNA knockdown of Nrf2 and PPAR $\alpha$

siRNA for Nrf2 and PPAR $\alpha$ were purchased from Santa Cruz Biotechnology (Dallas, TX). Scrambled non-specific siRNAs were applied as controls. $100 \mathrm{nM}$ (final concentration) siRNAs and $1 \mu \mathrm{g}$ of PGL3/4.5HO- 1 were co-transfected into A2780 cells cultured in a $60-\mathrm{mm}$ dish following the manufacturer's protocols. On the next day, cells were lifted and plated into 24 -well plates (for luciferase activity assay) or 100 -mm dishes (for Western blot analysis). 48 hours after the transfection, $\mathrm{ZnCl}_{2}$ was added to the medium at indicated concentrations for 8 hours. The cells were then lysated and assayed for luciferase activity. The knockdown of Nrf2 and PPAR $\alpha$ was confirmed by Western blot analysis.

Generation of PGL3/4.5-HO-1 mutants

The PGL3/4.5-HO-1 construct was served as a parental plasmid to generate mutants with the deletion of the two antioxidant response elements (AREs) $[16,17]$ and two peroxisome proliferator response element (PPREs) located within the promoter [18]. This was achieved by using the QuikChange Site-Directed Mutagenesis Kit (Stratagene, La Jolla, CA, USA). The primers used for mutations were as follows: ARE1 deletion (forward), 5'-CGTGCAGCTGCATTTCTTGTTTGGGAGGG-3'; ARE1 deletion (reverse): 5'-CCCTCCCAAACAAGAAATGCAGCTGCACG-3'; ARE2 deletion (forward): 5'-CGGATTTTGCTAGATTTCCAGTGCCTCCTCAGC-3'; ARE2 deletion (reverse): 5'-GCTGAGGAGGCACTGGAAAGAGAGCAAAATCCG -3'; PPRE1 deletion (forward): 5'- CTGCCTAGGATGTGCGGCTCCACC-3'; PPRE1 deletion (reverse): 5'- GGTGGAGCCGCACATCCTAGGCAG-3'; PPRE2 deletion (forward): 5'- CCTTCCCTTAAAGTCCAGGGCCATTCC-3'; PPRE2 deletion (reverse): 5'- GGAATGGCCCTGGACTTTAAGGGAAGG-3'. Single mutations were achieved first, and followed by Double mutations. The mutants were confirmed by direct DNA sequencing.

\section{Chromatin Immunoprecipitation Assay}

The ChIP assay was performed with a kit from Millipore (Billerica, MA) as we previously described [19]. In short, A2780 cells were treated with $100 \mu \mathrm{M} \mathrm{ZnCl}_{2}$ for 2 hours. Formaldehyde was then added directly to the medium (final concentration, $1 \%$ ) to cross-link the DNA and transcription factors at $37^{\circ} \mathrm{C}$ for 10 minutes. Cells were washed, removed from the dish, pelleted, and lysed on ice in the SDS buffer. The lysate was sonicated to shear the DNA into sizes ranging from 200 to $1000 \mathrm{bp}$ and the DNA was pre-cleared for 1 hour on ice with Protein A agarose/salmon sperm DNA (50\% slurry). The complex of protein and DNA was precipitated overnight at $4^{\circ} \mathrm{C}$ using Nrf2, or PPAR $\alpha$ antibody, and the complex was then incubated with Protein A agarose/salmon sperm DNA (50\% Slurry) for 2 hours at $4^{\circ} \mathrm{C}$, washed and eluted. The precipitants were then incubated with $\mathrm{NaCl}$ at $65^{\circ} \mathrm{C}$ for 4 hours to reverse DNA cross-links. The precipitants were then digested with protein kinase K, and DNA was extracted with phenol/chloroform and precipitated with etha- 


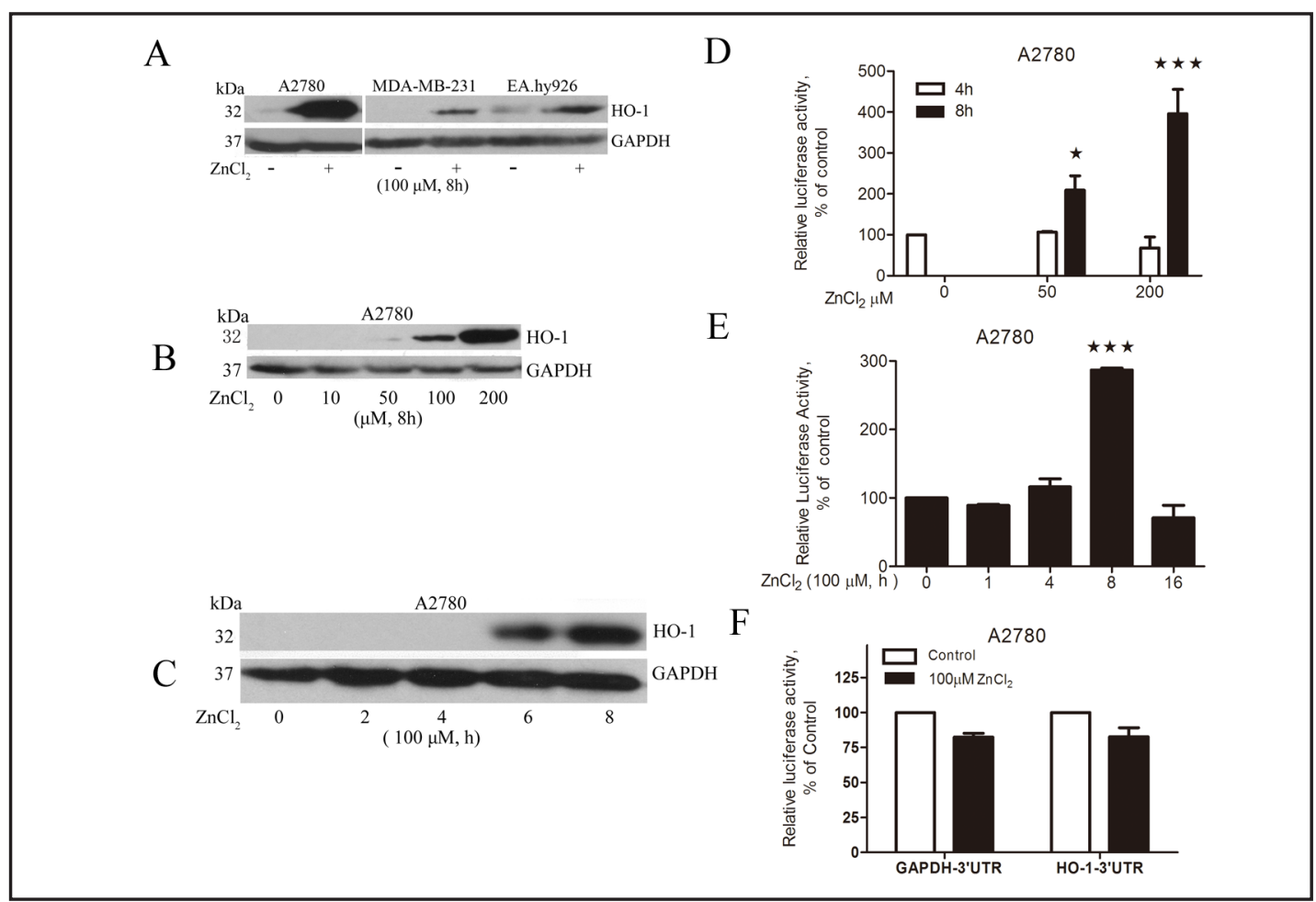

Fig. 1. Effects of $\mathrm{ZnCl}_{2}$ on HO-1 expression. (A). Induction of HO-1 in A2780, MDA-MB-231, and EA.hy926 cells after treatment with $\mathrm{ZnCl}_{2}$ at $100 \mu \mathrm{M}$ for 8 hours. Cell lysates were prepared and Western blot was performed using antibodies against HO-1 and GAPDH. (B). Concentration-dependent induction of HO-1 by $\mathrm{ZnCl}_{2}$ in A2780 cells after treatment with $\mathrm{ZnCl}_{2}$ at 50,100 , or $200 \mu \mathrm{M}$ for 8 hours. Cell lysates were prepared and Western blot was performed using antibodies against HO-1 and GAPDH. (C). Time-course induction of HO- 1 by $\mathrm{ZnCl}_{2}$ in $\mathrm{A} 2780$ cells after treatment with $\mathrm{ZnCl}_{2}$ at $100 \mu \mathrm{M}$ for 2, 4, 6 or 8 hours. Cell lysates were prepared and Western blot was performed using antibodies against HO-1 and GAPDH. Induction of HO-1 promoter activity by $\mathrm{ZnCl}_{2}$ in A2780 cells. Cells were transfected with the PGL3/4.5-HO-1 promoter reporter construct and treated with $\mathrm{ZnCl}_{2}$ at 50 or $200 \mu \mathrm{M}$ for 4 or 8 hours (D) or $100 \mu \mathrm{M}$ for 1, 4, 8 or 16 hours (E), 48 hours post transfection. Cell lysates were prepared, and luciferase activity was assayed. (F). $\mathrm{ZnCl}_{2}$ does not affect HO-1 3'UTR-mediated activity in A2780 cells. Cells were transfected with the HO-1 3'-UTR or the GAPDH 3'-UTR reporter construct and treated with $100 \mu \mathrm{M} \mathrm{ZnCl}_{2}$ for 8 hours after 48 hours of transfection. Cell lysates were prepared, and luciferase activity was assayed. Images are representative of three experiments. Data for luciferase activity are expressed as percentage of the value detected in untreated control cells (bars, SE; $\mathrm{n}=3$ ). * $\mathrm{P}<0.05$, ***, $\mathrm{P}<0.001$ using one-way ANOVA followed by Dunnett's analysis.

nol. DNA was analyzed by PCR amplification using primers specific to the promoter regions of interest. The samples were initially denatured at $94{ }^{\circ} \mathrm{C}$ for 5 minuts prior to thermal cycling. The thermal cycle for PCR consisted of $94{ }^{\circ} \mathrm{C}$ for 1 minute, $55^{\circ} \mathrm{C}$ (ARE1) or $45^{\circ} \mathrm{C}$ (PPRE1/2) for 1 minute, $72{ }^{\circ} \mathrm{C}$ for 2 minutes, total 35 cycles. The PCR products were separated on a $1 \%$ agarose gel containing ethidium bromide and visualized under ultraviolet light. The primers used for DNA amplification of DNA fragment in the HO-1 gene promoter were as follows: ARE1 (forward), 5'-CTG CCC AAA CCA CTT CTG TT-3'; ARE1 (reverse), 5'-GCA CTG GTG ACT CAG CAA AA -3' (-4082 to -4074); PPRE1/2 (forward) 5'-CTG GAG AGA GAA AGA GAC-3'; PPRE1/2 (reverse) 5'-GTG GAG TCA AGA GGC TAC-3' (-1881 to -1836).

\section{Statistical Analysis}

All statistical analysis was performed with Graphpad Prism software (San Diego, CA). One-way ANOVA with Dunnett's post-test was used to determine differences among control and experimental groups, with $\mathrm{p}<0.05, \mathrm{p}<0.01$, or $\mathrm{p}<0.001$ as the levels of statistical significance. 


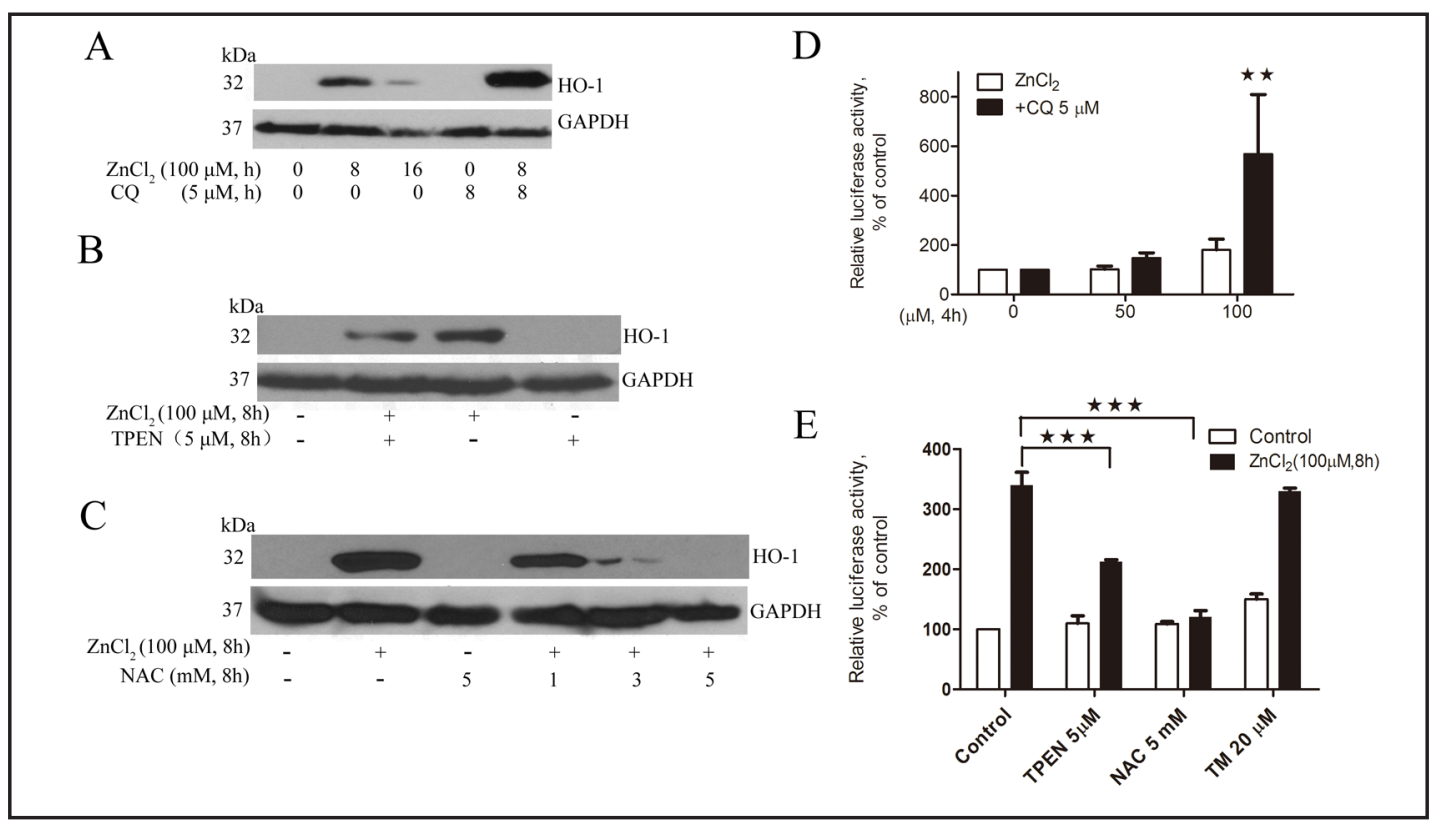

Fig. 2. Effects of clioquinol (CQ), TPEN, and $\mathrm{NAC}$ on $\mathrm{ZnCl}_{2}$-induced $\mathrm{HO}-1$ expression in $\mathrm{A} 2780$ cells. (A). CQ enhances $\mathrm{ZnCl}_{2}$-induced $\mathrm{HO}-1$ protein expression. Cells were treated with $100 \mu \mathrm{M} \mathrm{ZnCl}_{2}$ for 8 or 16 hours in the presence or absence of $5 \mu \mathrm{M}$ CQ. Cell lysates were prepared and Western blot was performed using antibodies against HO-1 and GAPDH. (B). TPEN reverses $\mathrm{ZnCl}_{2}$-induced HO-1 protein expression. Cells were treated with $100 \mu \mathrm{M} \mathrm{ZnCl}_{2}$ for 8 hours in the presence and absence of $5 \mu \mathrm{M}$ TPEN. Cell lysates were prepared and Western blot was performed using antibodies against HO-1 and GAPDH. (C). NAC reverses $\mathrm{ZnCl}_{2}$-induced H0-1 protein expression. Cells were treated with $100 \mu \mathrm{M} \mathrm{ZnCl}_{2}$ for 8 hours in the presence or absence of 1,3, or 5 mM NAC. Cell lysates were prepared and Western blot was performed using antibodies against HO-1 and GAPDH. (D). CQ enhances $\mathrm{ZnCl}_{2}$-induced HO-1 promoter activity. Cells were transfected with the PGL3/4.5-HO-1 promoter reporter construct and treated with $50 \mu \mathrm{M}$ or $100 \mu \mathrm{M} \mathrm{ZnCl}_{2}$ for 4 hours in the presence or absence of $5 \mu \mathrm{M}$ CQ after 48 hours of transfection. Cell lysates were prepared, and luciferase activity was assayed. (E). TPEN and NAC, but not TM (a copper chelator) reverse $\mathrm{ZnCl}_{2}$-induced HO-1 promoter activity. Cells were transfected with the PGL3/4.5-HO-1 promoter reporter construct and treated with $100 \mu \mathrm{M} \mathrm{ZnCl}_{2}$ for 8 hours in the presence or absence of $5 \mu \mathrm{M}$ TPEN, $5 \mathrm{mM} \mathrm{NAC}$, or $20 \mu \mathrm{M}$ TM after 48 hours of transfection. Cell lysates were prepared, and luciferase activity was assayed. Data are expressed as percentage of the value detected in untreated control cells (bars, $\mathrm{SE} ; \mathrm{n}=3$ ). ${ }^{* *}, \mathrm{P}<0.01, * * *, \mathrm{P}<0.001$, compared with treated control cells, using one-way ANOVA followed by Dunnett's analysis.

\section{Results}

We have previously demonstrated that $\mathrm{ZnCl}_{2}$ at $50-100 \mu \mathrm{M}$ is not cytotoxic to human cancer cells $[9,20,21]$. To investigate whether zinc at these concentrations affects HO-1 gene expression, the human ovarian cancer cell line (A2780), the breast cancer cell line (MDAMB-231), and the non-cancerous umbilical vein endothelial cell line (EA.hy926) were treated with $\mathrm{ZnCl}_{2}$ at the indicated concentrations and durations. Western blot was performed to analyze HO-1 protein expression. As shown in Figure 1A, the basal level of HO-1 protein expression is barely detectable in all cell lines examined, consistent with our recent report [22]. However, treatment with $\mathrm{ZnCl}_{2}$ significantly induced HO-1 expression (Fig. 1A), with initial detection at 6 hours of treatment and maximal induction at 8 hours in A2780 cells (Fig. 1C). The induction of $\mathrm{HO}-1$ expression by $\mathrm{ZnCl}_{2}$ was also concentration-dependent (Fig. 1B).

To determine whether the induction of $\mathrm{HO}-1$ expression by $\mathrm{ZnCl}_{2}$ is mediated at the transcriptional or post-transcriptional level, the PGL3/4.5-HO-1 promoter reporter construct or the HO-1-3'-UTR reporter construct was transfected into A2780 cells, and the cells 

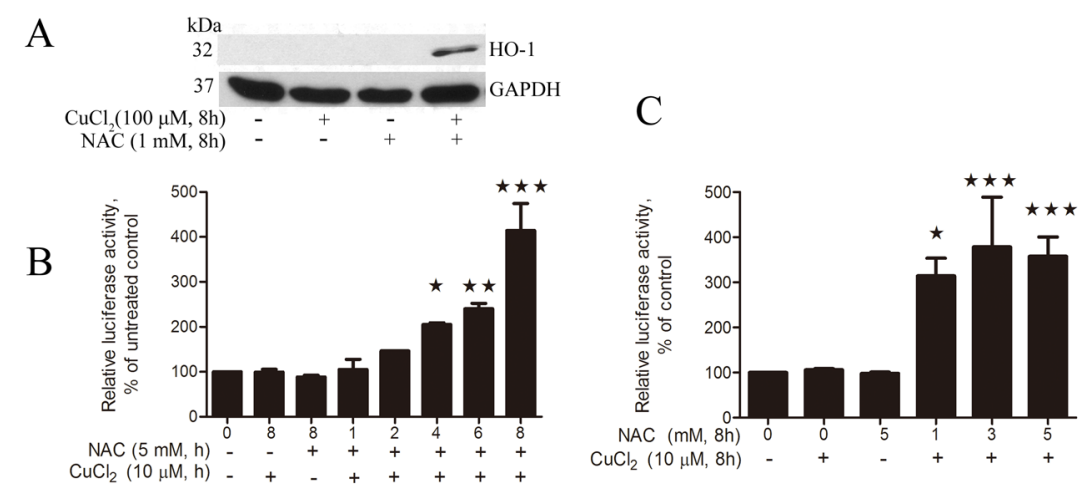

Fig. 3. Effects of $\mathrm{CuCl}_{2}$ plus $\mathrm{NAC}$ on $\mathrm{HO}-1$ expression in $\mathrm{A} 2780$ cells. (A). $\mathrm{CuCl}_{2}$ plus $\mathrm{NAC}$ induces $\mathrm{HO}-1$ protein expression. Cells were treated with $10 \mu \mathrm{M} \mathrm{CuCl}_{2}$ for 8 hours in the presence or absence of $1 \mathrm{mM}$ NAC. Cell lysates were prepared and Western blot was performed using antibodies against HO-1 and GAPDH. (B). Time-course of $\mathrm{CuCl}_{2}$ plus NAC-induced HO-1 promoter activity. Cells were transfected with the PGL3/4.5HO-1 promoter reporter construct and treated with $10 \mu \mathrm{M} \mathrm{CuCl}_{2}$ in the presence or absence of $5 \mathrm{mM} \mathrm{NAC}$ for 1, 2, 4, 6 or 8 hours. Cell lysates were prepared, and luciferase activity was assayed. (C). Concentrationdependent induction of HO-1 promoter activity by $\mathrm{CuCl}_{2}$ plus NAC. Cells were transfected with the PGL3/4.5HO-1 promoter reporter construct and treated with $10 \mu \mathrm{M} \mathrm{CuCl}_{2}$ for 8 hours in the presence or absence of 1,3 , or 5 mM NAC. Cell lysates were prepared, and luciferase activity was assayed. Data are expressed as percentage of the value detected in untreated control cells (bars, SE; $\mathrm{n}=3$ ). ${ }^{*}, \mathrm{P}<0.05 * *, \mathrm{P}<0.01, * * *$, $\mathrm{P}<0.001$, compared with untreated control cells, using one-way ANOVA followed by Dunnett's analysis.

Fig. 4. Effects of knockdown of Nrf2 or PPAR $\alpha$ on $\mathrm{ZnCl}_{2}$-induced increase in $\mathrm{HO}-1$ promoter activity. (A). siRNA knockdown of Nrf2 and PPAR $\alpha$ expression in A2780 cells. Cells were transfected with $100 \mathrm{nM}$ scrambled siRNA, Nrf2 siRNA (left panel) or PPAR $\alpha$ siRNA (right panel). After 48 hours, cell lysates were prepared and Western blot was performed using antibodies against Nrf2, PPAR $\alpha$ and GAPDH. (B). Knockdown of Nrf2 but not PPAR $\alpha$ reverses $\mathrm{ZnCl}_{2}$-induced HO-1 promoter activity. A2780 cells were co-transfected with the PGL3/4.5-HO-1 promoter reporter construct and scrambled siRNA, Nrf2 siRNA, or PPAR $\alpha$ siRNA. Forty-eight hours after transfection cells were treated with $100 \mu \mathrm{M} \mathrm{ZnCl}_{2}$ for 8 hours. Cell lysates were prepared, and luciferase activity was assayed. Data are expressed as percentages of the value detected in untreated control cells (bar, $S E, n=3$ ). $*, \mathrm{P}<0.05$, using one-way ANOVA followed by Dunnett's analysis.

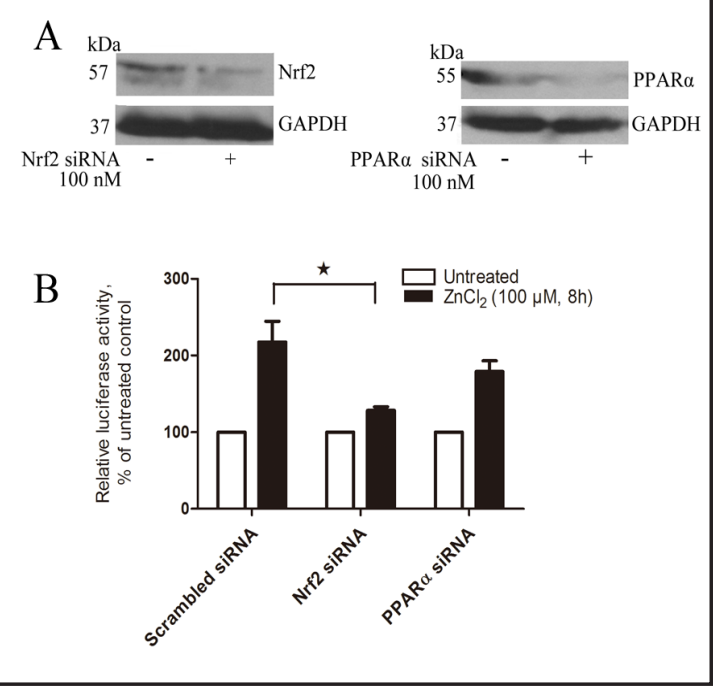

were treated with $50-200 \mu \mathrm{M} \mathrm{ZnCl}_{2}$ for 1-16 hours. The luciferase reporter activity assay indicated that HO-1 promoter activity is significantly induced by $\mathrm{ZnCl}_{2}$ in a concentration- and time-dependent manner (Fig. 1D, E), whereas the HO-1-3'-UTR- and GAPDH-3'-UTR-mediated luciferase activity remains unchanged after the treatment (Fig. 1F). These results clearly indicate that the observed $\mathrm{ZnCl}_{2}$-induced increase in $\mathrm{HO}-1$ expression is mediated the transcriptional level, with peak induction of HO-1 promoter activity at 8 hours of treatment and declined thereafter. 
Fig. 5. Effects of $\mathrm{ZnCl}_{2}$ on $\mathrm{Nrf2}$ expression in A2780 cells. $\mathrm{ZnCl}_{2}$ treatment increases cellular (A) and nuclear (B) Nrf2 protein expression. A2780 cells were treated with $\mathrm{ZnCl}_{2}$ at the indicated concentrations and durations. Cellular and nuclear proteins were extracted and Western blot was performed using antibodies against Nrf2, $\beta$-actin and GAPDH. Images are representatives of three experiments.

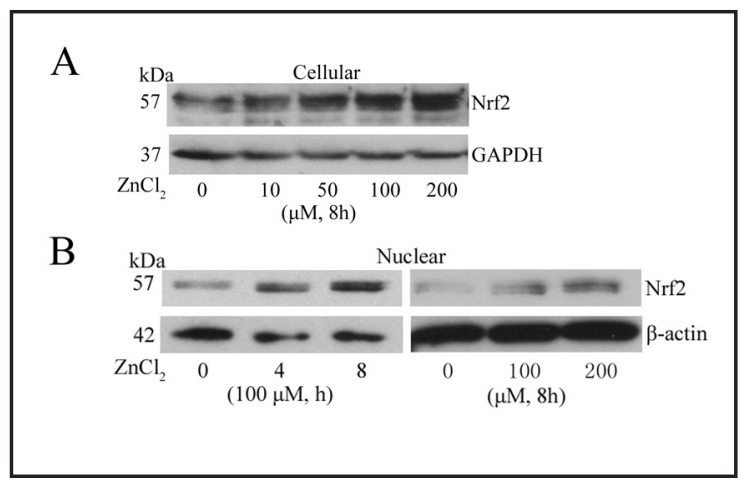

Fig. 6. The contribution of the AREs in the HO-1 gene promoter to $\mathrm{ZnCl}_{2}$-induced increase in $\mathrm{HO}-1$ gene transcription. (A). A diagram showing the relative positions of the AREs and PPREs in human HO-1 gene promoter. (B). Deletion of the AREs but not the PPREs reverses $\mathrm{ZnCl}_{2}$-induced $\mathrm{HO}-1$ promoter activity. A2780 cells were transfected with the PGL3/4.5-HO-1 promoter reporter constructs and its single deletion (ARE1, ARE2) or double deletion (ARE1/2, PPRE1/2) mutants treated with $\mathrm{ZnCl}_{2}$ at $100 \mu \mathrm{M}$ for 8 hours after 48 hours of transfection. Cell lysates were prepared and luciferase activity was assayed. Data are expressed as percentages of the value detected in untreated control cells (bar, $\mathrm{SE}, \mathrm{n}=3$ ). *, $\mathrm{P}<0.05$, using one-way ANOVA followed by Dunnett's analysis.

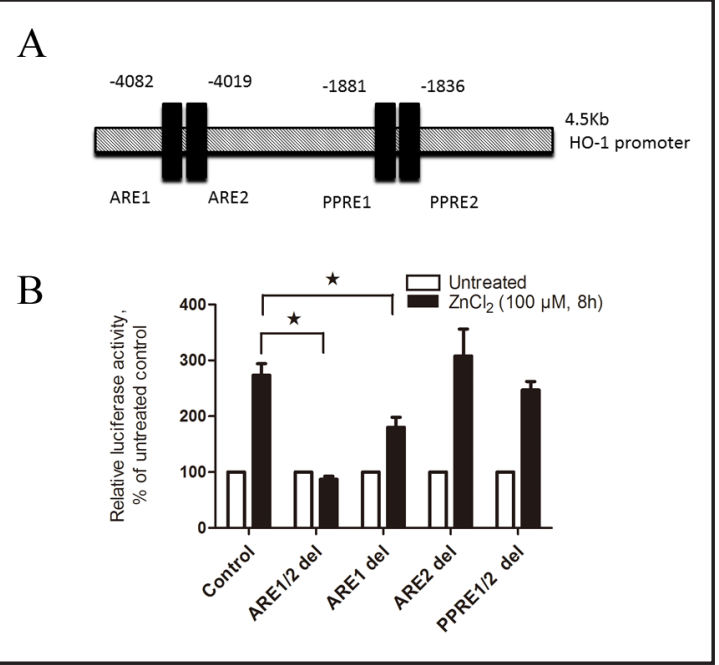

To understand whether the $\mathrm{ZnCl}_{2}$-induced $\mathrm{HO}-1$ expression is due to an increase in intracellular zinc, A2780 cells were treated with $\mathrm{ZnCl}_{2}$ in the presence or absence of clioquinol (CQ), a well-established zinc ionophore [12]. Addition of CQ (5 $\mu \mathrm{M})$ significantly enhanced zinc-induced HO-1 gene expression and promoter activity (Fig. 2A, D), supporting the idea that increased intracellular zinc accounts for the induction of HO-1. Furthermore, when A2780 cells were pretreated with TPEN, a well-known high-affinity zinc chelator [23], Zn$\mathrm{Cl}_{2}$-induced HO-1 expression was abolished (Fig. 2B, E), further indicating that the increase in intracellular zinc is responsible for HO-1 induction. On the other hand, TM, a well-established copper chelator [24], had no effect on $\mathrm{ZnCl}_{2}$-induced HO-1 promoter activity (Fig. 2E). Interestingly, $\mathrm{NAC}$, a broadly used antioxidant, blocked $\mathrm{ZnCl}_{2}$-induced $\mathrm{HO}-1$ expression and promoter activity (Fig. 2C, E), suggesting a possibility that $\mathrm{ZnCl}_{2}$ may induce a transient elevation of oxidative stress in this model system. Elevation of intracellular free zinc levels has been shown to induce oxidative stress in mammalian cells [25]. Because we have recently reported that NAC may interact with copper to generate hydrogen peroxides thus turning an antioxidant into a pro-oxidant [26], we tested the effect of the combination of NAC and copper on HO-1 expression in A2780 cells. As expected, NAC plus $\mathrm{CuCl}_{2}$ induced $\mathrm{HO}-1$ expression and promoter activity in this model system (Fig. 3A-C).

HO-1 gene transcription is typically regulated by the Nrf2 signaling pathway [27]. To determine whether $\mathrm{Nrf} 2$ mediates $\mathrm{ZnCl}_{2}$-induced $\mathrm{HO}-1$ expression in our model system, a sequence specific siRNA was applied to knockdown Nrf2 expression in A2780 cells (Fig. 4A). Knockdown of Nrf2 dramatically attenuated the $\mathrm{ZnCl}_{2}$-induced increase of $\mathrm{HO}-1$ promoter activity (Fig. 4B), whereas no significant change was observed after knockdown of PPAR $\alpha$ (Fig. 4A and B), another transcription factor known to regulate HO-1 expression [18]. These 
Fig. 7. Effects of $\mathrm{ZnCl}_{2}$ on $\mathrm{Nrf2}$ binding to endogenous ARE1 in the HO-1 gene promoter. $\mathrm{ZnCl}_{2}$ increases $\mathrm{Nrf} 2$ binding to the ARE1 (A), but has no effect on PPAR $\alpha$ binding to the PPRE (B). A2780 cells were treated with $100 \mu \mathrm{M} \mathrm{ZnCl}_{2}$ for 2 hours. ChIP assay was performed as described in the Material and Methods section. The amplified DNA fragments were separated on 1\% agarose gel and visualized under ultraviolet light. Shown are representative gel images of 2 separate experiments.

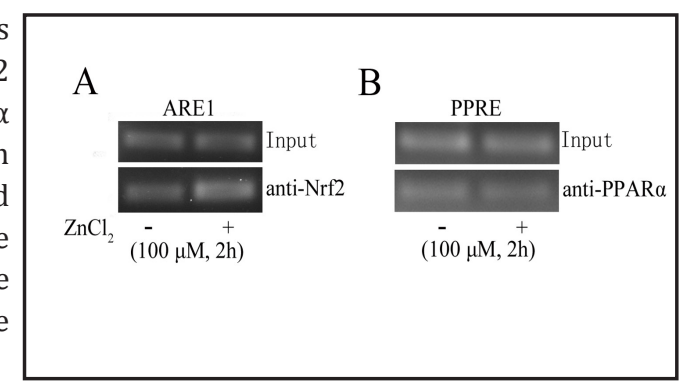

results support the conclusion that the $\mathrm{Nrf} 2$ signaling pathway mediates $\mathrm{ZnCl}_{2}$-induced enhancement of HO-1 gene transcription. Western blot analysis confirmed that treatment with $\mathrm{ZnCl}_{2}$ increases Nrf2 protein expression at both cytoplasmic and nuclear levels in a concentration- (Fig. 5A) and time-dependent (Fig. 5B) manner.

In the typical scenario, upon activation, Nrf2 will translocate into the nucleus, bind to the AREs and activate HO-1 gene transcription [27]. There are two adjacent AREs identified in the human HO-1 gene promoter (Fig. 6A) [28]. In an attempt to identify the DNA binding elements that mediate $\mathrm{ZnCl}_{2}$-induced $\mathrm{HO}-1$ gene transcription, we deleted the two ARE elements from the HO-1 gene promoter construct (pGL3/4.5-HO-1). The two PPRE elements identified in this promoter were also deleted. As shown in Fig. 6B, single deletion of ARE1 (the distal ARE) significantly compromised the $\mathrm{ZnCl}_{2}$-induced increase in $\mathrm{HO}-1$ promoter activity. Deletion of both ARE elements completely reversed the $\mathrm{ZnCl}_{2}$-induced increase in HO-1 promoter activity. In contrast, deletion of both PPRE elements did not significantly alter $\mathrm{ZnCl}_{2}$-induced increase in $\mathrm{HO}-1$ promoter activity (Fig. 6B). These results indicate that the AREs primarily mediate this event. ChIP analysis was applied to examine the DNA binding activity of Nrf2 in cells that had been treated with $\mathrm{ZnCl}_{2}$. The PPAR $\alpha$ binding to PPRE was also analyzed as a control. These results show that Nrf2 binding to ARE1 was significantly enhanced while PPAR $\alpha$ binding to the PPRE remained unchanged by $\mathrm{ZnCl}_{2}$ treatment (Fig. 7).

\section{Discussion}

While zinc is known to be involved in the carcinogenesis of various types of cancer [68], the interaction of zinc with cellular antioxidant enzymes in breast and ovarian cancer cells has never been previously examined. We demonstrated in this study that zinc at sub-cytotoxic concentrations induces HO-1 gene transcription through the Nrf2 signaling pathway in human breast and ovarian cancer cell model systems. As zinc is considered an anticancer agent against various types of malignancy [10] and HO-1 has been shown to induce chemo-resistance of cancer cells [2-4], these findings implicate a new angle in understanding zinc's anticancer activity. Specifically, zinc at sub-cytotoxic concentrations may have a preventive effect against carcinogenesis because of the up-regulation of HO-1 expression in normal cells, while it may compromise the effectiveness of chemotherapy as it induces HO-1 expression in cancer cells.

Induction of HO-1 in breast and ovarian cancer cells by zinc has not been previously investigated. The present study showed that treatment with zinc induces HO-1 expression in both breast and ovarian cancer model systems. The induction clearly takes place at the transcription level, as both protein expression and the HO-1 promoter-driven reporter activity are up-regulated by zinc. Furthermore it was demonstrated that it is not extracellular zinc ions that induce HO-1 expression, rather it is the increase in intracellular zinc that enhances HO-1 gene transcription; as evidenced by the addition of a zinc chelator to reverse the induction, and a zinc ionophore to further enhance the induction. It is interesting to note that 
HO-1 induction is also relatively transient, being detected at 4 hours after zinc treatment and at maximum induction at 8 hours, and declined thereafter, which is reminiscent of HO-1 induction seen in different experimental model systems [29-31]. As a consequence of HO-1 induction, cancer cells may develop chemo-resistance [2], implying that zinc at sub-cytotoxic concentrations may increase chemo-resistance of cancer cells. On the other hand, previous reports have also indicated that supplementation with zinc may restore p53 function and suppress HIF- $1 \alpha$ activity, thereby sensitizing cancer cells to chemotherapy in vivo [32, 33]. Thus, the biological consequences of zinc-induced HO-1 expression in cancer cells merit further investigation.

Zinc is known to regulate gene transcription in many model systems [34]. We have previously reported that NF-kappa B and PPAR $\alpha$ signaling are involved in zinc ionophore-induced anticancer activity $[9,35]$ and that zinc at cytotoxic concentrations could alter post-transcriptional events of gene expression in cancer cells [13]. In the present study, we have obtained strong evidence indicating that zinc-induced HO-1 expression is mediated through transcriptional regulation via the Nrf2 signaling pathway. First, we knocked down Nrf2 or PPAR $\alpha$ expression and observed that only $\mathrm{Nrf} 2$ knockdown attenuated the $\mathrm{ZnCl}_{2}$-induced HO-1 gene transcription; indicating that the Nrf2 signaling pathway, but not the PPAR $\alpha$ pathway, is involved in this event. Second, deletion of the AREs from the HO-1 gene promoter abolished $\mathrm{ZnCl}_{2}$-induced HO-1 gene promoter activity, while deletion of the PPREs had no significant effect on the induction. The ARE is an established DNA cis-element bound by Nrf2 [1]. Third, nuclear Nrf2 levels and Nrf2 binding to the ARE1 in the HO-1 gene promoter was significantly increased by zinc treatment, confirming that zinc activates the Nrf2 signaling pathway leading to enhanced HO-1 gene expression. Finally, when NAC, an antioxidant was applied, the zinc-induced H0-1 expression was attenuated, suggesting that a certain level of oxidative stress is involved in HO-1 induction, which is consistent with the fact that up-regulation of the Nrf2 pathway is often associated with increased oxidative stress [1]. While zinc is generally considered an antioxidant, high levels of free intracellular zinc ion have been described to facilitate oxidative stress in mammalian cell model system [25].

In summary, we have demonstrated that zinc at sub-cytotoxic concentrations transiently induces HO-1 expression in breast and ovarian cancer model systems, which is mediated through the Nrf2 signaling pathway. These findings implicate that the effective application of zinc as an anticancer agent, whether for prevention or therapy, may depend on the concentrations used, a concept worth further exploration.

\section{Acknowledgements}

This work was supported in part by grants from the American Cancer Society (CNE117557); the Susan G. Komen for the Cure Foundation (KG081083); the NIH OK-INBRE program (3P20RR016478-09S2); and the Oklahoma Center for the Advancement of Science and Technology (HR09-025).

\section{References}

-1 Loboda A, Jazwa A, Grochot-Przeczek A, Rutkowski AJ, Cisowski J, Agarwal A, Jozkowicz A, Dulak J: Heme oxygenase- 1 and the vascular bed: From molecular mechanisms to therapeutic opportunities. Antioxid Redox Signal 2008;10:1767-1812.

$>2$ Fang J, Nakamura H, Iyer AK: Tumor-targeted induction of oxystress for cancer therapy. J Drug Target 2007;15:475-486. 
Xue et al.: Zinc Induces HO-1 Expression in Cancer Cells

3 Nuhn P, Kunzli BM, Hennig R, Mitkus T, Ramanauskas T, Nobiling R, Meuer SC, Friess H, Berberat PO: Heme oxygenase-1 and its metabolites affect pancreatic tumor growth in vivo. Mol Cancer 2009;8:37.

4 Gleixner KV, Mayerhofer M, Vales A, Gruze A, Hormann G, Cerny-Reiterer S, Lackner E, Hadzijusufovic E, Herrmann H, Iyer AK, Krauth MT, Pickl WF, Marian B, Panzer-Grumayer R, Sillaber C, Maeda H, Zielinski C, Valent P: Targeting of hsp32 in solid tumors and leukemias: A novel approach to optimize anticancer therapy. Curr Cancer Drug Targets 2009;9:675-689.

5 Chasapis CT, Loutsidou AC, Spiliopoulou CA, Stefanidou ME: Zinc and human health: An update. Arch Toxicol 2012;86:521-534.

6 Alam S, Kelleher SL: Cellular mechanisms of zinc dysregulation: A perspective on zinc homeostasis as an etiological factor in the development and progression of breast cancer. Nutrients 2012;4:875-903.

7 Alder H, Taccioli C, Chen H, Jiang Y, Smalley KJ, Fadda P, Ozer HG, Huebner K, Farber JL, Croce CM, Fong LY: Dysregulation of mir-31 and mir-21 induced by zinc deficiency promotes esophageal cancer. Carcinogenesis 2012;33:1736-1744.

8 Costello LC, Franklin RB: Zinc is decreased in prostate cancer: An established relationship of prostate cancer! J Biol Inorg Chem 2011;16:3-8.

-9 Ding WQ, Liu B, Vaught JL, Yamauchi H, Lind SE: Anticancer activity of the antibiotic clioquinol. Cancer Res 2005;65:3389-3395.

10 Ding WQ, Lind SE: Metal ionophores - an emerging class of anticancer drugs. IUBMB Life 2009;61:10131018.

11 Chen D, Cui QC, Yang H, Barrea RA, Sarkar FH, Sheng S, Yan B, Reddy GP, Dou QP: Clioquinol, a therapeutic agent for alzheimer's disease, has proteasome-inhibitory, androgen receptor-suppressing, apoptosis-inducing, and antitumor activities in human prostate cancer cells and xenografts. Cancer Res 2007;67:16361644.

-12 Yu H, Zhou Y, Lind SE, Ding WQ: Clioquinol targets zinc to lysosomes in human cancer cells. Biochem J 2009;417:133-139.

13 Zheng J, Zhang XX, Yu H, Taggart JE, Ding WQ: Zinc at cytotoxic concentrations affects posttranscriptional events of gene expression in cancer cells. Cell Physiol Biochem 2012;29:181-188.

14 Zhang X, Yu H, Lou JR, Zheng J, Zhu H, Popescu NI, Lupu F, Lind SE, Ding WQ: Microrna-19 (mir-19) regulates tissue factor expression in breast cancer cells. J Biol Chem 2011;286:1429-1435.

15 Zhou J, Zhang S, Xue J, Avery J, Wu J, Lind SE, Ding WQ: Activation of peroxisome proliferator-activated receptor alpha (pparalpha) suppresses hypoxia-inducible factor-1alpha (hif-1alpha) signaling in cancer cells. J Biol Chem 2012;287:35161-35169.

16 Rushworth SA, Chen XL, Mackman N, Ogborne RM, O'Connell MA: Lipopolysaccharide-induced heme oxygenase-1 expression in human monocytic cells is mediated via nrf2 and protein kinase c. J Immunol 2005;175:4408-4415.

17 Rushworth SA, MacEwan DJ: Ho-1 underlies resistance of aml cells to tnf-induced apoptosis. Blood 2008;111:3793-3801.

18 Kronke G, Kadl A, Ikonomu E, Bluml S, Furnkranz A, Sarembock IJ, Bochkov VN, Exner M, Binder BR, Leitinger N: Expression of heme oxygenase-1 in human vascular cells is regulated by peroxisome proliferator-activated receptors. Arterioscler Thromb Vasc Biol 2007;27:1276-1282.

19 Tuller ER, Beavers CT, Lou JR, Ihnat MA, Benbrook DM, Ding WQ: Docosahexaenoic acid inhibits superoxide dismutase 1 gene transcription in human cancer cells: The involvement of peroxisome proliferator-activated receptor alpha and hypoxia-inducible factor-2alpha signaling. Mol Pharmacol 2009;76:588-595.

20 Ding WQ, Yu HJ, Lind SE: Zinc-binding compounds induce cancer cell death via distinct modes of action. Cancer Lett 2008;271:251-259.

-21 Jiang H, Taggart JE, Zhang X, Benbrook DM, Lind SE, Ding WQ: Nitroxoline (8-hydroxy-5-nitroquinoline) is more a potent anti-cancer agent than clioquinol (5-chloro-7-iodo-8-quinoline). Cancer Lett 2011;312:1117.

22 Wang S, Avery JE, Hannafon BN, Lind SE, Ding WQ: Zinc protoporphyrin suppresses cancer cell viability through a heme oxygenase-1-independent mechanism: The involvement of the wnt/beta-catenin signaling pathway. Biochem Pharmacol 2013;85:1611-1618.

23 Canzoniero LM, Manzerra P, Sheline CT, Choi DW: Membrane-permeant chelators can attenuate $\mathrm{Zn}^{2+}$-induced cortical neuronal death. Neuropharmacology 2003;45:420-428. 
24 Medici V, Sturniolo GC: Tetrathiomolybdate, a copper chelator for the treatment of wilson disease, pulmonary fibrosis and other indications. IDrugs 2008;11:592-606.

25 Wiseman DA, Sharma S, Black SM: Elevated zinc induces endothelial apoptosis via disruption of glutathione metabolism: Role of the adp translocator. Biometals 2010;23:19-30.

-26 Zheng J, Lou JR, Zhang XX, Benbrook DM, Hanigan MH, Lind SE, Ding WQ: N-acetylcysteine interacts with copper to generate hydrogen peroxide and selectively induce cancer cell death. Cancer Lett 2010;298:186194.

27 Srisook K, Kim C, Cha YN: Molecular mechanisms involved in enhancing ho-1 expression: De-repression by heme and activation by nrf2, the "one-two" punch. Antioxid Redox Signal 2005;7:1674-1687.

28 Wright MM, Kim J, Hock TD, Leitinger N, Freeman BA, Agarwal A: Human haem oxygenase-1 induction by nitro-linoleic acid is mediated by camp, ap-1 and e-box response element interactions. Biochem J 2009;422:353-361.

29 Durante W, Peyton KJ, Schafer AI: Platelet-derived growth factor stimulates heme oxygenase-1 gene expression and carbon monoxide production in vascular smooth muscle cells. Arterioscler Thromb Vasc Biol 1999;19:2666-2672.

-30 Liang M, Croatt AJ, Nath KA: Mechanisms underlying induction of heme oxygenase- 1 by nitric oxide in renal tubular epithelial cells. Am J Physiol Renal Physiol 2000;279:F728-735.

-31 Rothfuss A, Radermacher P, Speit G: Involvement of heme oxygenase-1 (ho-1) in the adaptive protection of human lymphocytes after hyperbaric oxygen (hbo) treatment. Carcinogenesis 2001;22:1979-1985.

-32 Margalit O, Simon AJ, Yakubov E, Puca R, Yosepovich A, Avivi C, Jacob-Hirsch J, Gelernter I, Harmelin A, Barshack I, Rechavi G, D'Orazi G, Givol D, Amariglio N: Zinc supplementation augments in vivo antitumor effect of chemotherapy by restoring p53 function. Int J Cancer 2012;131:E562-568.

-33 Nardinocchi L, Pantisano V, Puca R, Porru M, Aiello A, Grasselli A, Leonetti C, Safran M, Rechavi G, Givol D, Farsetti A, D'Orazi G: Zinc downregulates hif-1alpha and inhibits its activity in tumor cells in vitro and in vivo. PloS one 2010;5:e15048.

34 O'Halloran TV: Transition metals in control of gene expression. Science 1993;261:715-725.

-35 Tuller ER, Brock AL, Yu H, Lou JR, Benbrook DM, Ding WQ: Pparalpha signaling mediates the synergistic cytotoxicity of clioquinol and docosahexaenoic acid in human cancer cells. Biochem Pharmacol 2009;77:1480-1486. 